\title{
Product competition and $R \& D$ investment under spillovers within full or partial collusion games
}

\author{
Kai Zhao'
}

Received: 22 March 2014/Revised: 26 November 2014/Accepted: 8 April 2015/

Published online: 29 April 2015

(C) The Author(s) 2015. This article is published with open access at Springerlink.com

\begin{abstract}
The paper investigates firms' behavior and outcomes (levels of costreducing $R \& D$, output, profit and welfare in equilibrium) in a differentiated duopoly with process innovation. One of the important features in this paper is that spillovers operate in the R\&D stage and are tied to the degree of product substitutability as well as the extent of technological proximity/alienation of the research paths leading to cost reduction. Using this feature, the paper tries to explore and compare four separate organization setups (Full Competition, Semi-collusion in Production, Semicollusion in R\&D and Full Collusion). It is found that under technological proximity, competitions at the upstream stage depress R\&D investment, and firms colluding in R\&D regardless of their production strategy always yield more profit and generate higher social welfare than firms colluding in output; under technological alienation, $R \& D$ cooperation may reduce firms' interest to invest in $R \& D$, and it is possible that firms in the Full Collusion regime produce most and generate the highest level of social welfare.
\end{abstract}

Keywords R\&D $\cdot$ Spillover $\cdot$ Semi-collusion $\cdot$ Product differentiation $\cdot$ Horizontal merger

JEL Classification $\quad$ D43 $\cdot$ L13 $\cdot$ O31

Kai Zhao

kai.zhao@hotmail.fr

1 Institute for quantitative economics, Research center for the applied statistics and big data, Huaqiao University, 668, Jimei Avenue, 361021 Xiamen, China 


\section{Introduction}

Nowadays, economies in Latin America are becoming more and more knowledge based. Innovation becomes essential to spur economic growth and to raise living standards. At the firm level, either competition or collusion could reward innovation by providing strong incentives for firms to be more efficient than their rivals. This paper aims to study the extent to which innovation incentives in a duopoly change according to the extent of product substitutability and the "technological distance" of firms. We draw particular attention to firms' (full/partial) collusive behavior and attempt to address the following questions: What type of collusion (partial, full, none) should firms choose, and which one is more conducive to technological advancement and a firm's growth? How do firms choose different types of collusion, and how do these affect market outcomes? Can the collusive strategy improve the consumer surplus and the social welfare, and which one serves best?

Innovation through $R \& D$ investment leads to more efficient use of resources, creating sustainable competitive advantages. The most important aspect of R\&D investment is the externality (spillovers) which has been studied through the divergence between the social and private returns of production process. The public goods feature of knowledge generates spillovers which allow others to use the owner's innovation free of charge. Due to the spillover effect, the rate of return from an innovation is lesser and as a result, the incentives for carrying out R\&D are reduced. The individual firm fears that competitors use its internal research results and thus probably increase their profits without having to bear the expenses. Therefore, the researching firm will only have limited incentive to invest in R\&D. However, from the collective viewpoint, spillovers strengthen the dissemination of new knowledge available for the whole society, and improve the social welfare (Amir 2000).

Within a game where firms are first engaged in costly research efforts to adopt a lower-cost technology and then compete in a Cournot fashion with homogeneous products, (D'Aspremont and Jacquemin 1988) (henceforth "AJ") show that firms invest more under $R \& D$ cooperation than under $R \& D$ competition for sufficiently high spillover effects (full competition versus full cooperation). Kamien et al. (1992) (henceforth "KMZ") extend the AJ model to a more general framework with product differentiation and allow firms to participate in a research joint venture (RJV). They show that firms should be encouraged to form a RJV only if they coordinate their R\&D decisions while maintaining competition for sales. Concerning the welfare effects of cooperative $R \& D$ with spillovers, cooperation raises social welfare when the spillover is high (Suzumura 1992).

Compared to aforementioned works, this paper emphasizes the "close relationship" between product differentiation and R\&D spillovers. The key feature is to consider that the extent of product differentiation determines the ability of a firm to appropriate its rival's R\&D effort. In addition, this ability is influenced by the sensibility of spillovers relative to product differentiation, in other words, technological distance. Several explanations can be provided to justify this "close relationship". First, when products are close substitutes, R\&D efforts are less firm 
specific and a firm can more easily benefit from the discovery of a more efficient production technique resulting from rival's R\&D effort. Second, the exchange of technological information between engineers of competing firms is recognized as an important source of R\&D spillovers (Severinov 2001). Spillovers are believed to be higher between technological neighbors. According to this view, the ability to make productive use of another firm's knowledge depends on the degree of technological distance between firms. Every technology has a somewhat unique set of applications and language. Researchers in similar technological fields will interact in professional organizations, publish in commonly read journals, and, increasingly, browse a common set of web pages. It is natural to consider that the dissemination of technological knowledge across competing firms is strong when firms' technologies are similar. Furthermore, the above-mentioned "close relationship" is divided into two categories: concave relationship (technological proximity) where firms adopt similar technologies (i.e., the similar smart phones produced by Apple, Blackberry, Nokia ...), convex relationship (technological alienation) where firms adopt different technologies (i.e., electricity can be produced by different technologies). To be more concrete, we take the electricity production, for example, electric power companies are differentiated by voltages, a commercial consumer may need a voltage level of $11 \mathrm{kV}$ or $440 \mathrm{~V}$ while a residential consumer needs power at level of $240 \mathrm{~V}$, this difference of voltages refers to product differentiation. The electricity can be produced by different technologies (i.e., solar panels, wind turbines, nuclear energy), this refers to the extent of technological distance. The R\&D flow between companies employing the same output (voltage) and the same technique is obviously greater.

In location models, the distance between firms determines the degree of product differentiation. By considering that R\&D spillover depends negatively on firms' product location, it is shown that $R \& D$ effort is positively associated with the differentiation of products $^{1}$ (Piga and Poyago-Theotoky 2005). However, they do not address the important issue of cooperative behavior between firms in their models.

In this paper, we consider a two-stage game where firms with heterogeneous products competing in a Cournot fashion engage in upstream R\&D and downstream production. At each stage, the competing firms can either coordinate their decisions or adopt non-cooperative strategy. This assumption allows us to compare the Subgame Perfect Nash Equilibrium (henceforth "SPNE") emerging in the four separate scenarios : full competition, semi-collusion in Production ${ }^{2}$, Semi-collusion in R\&D ${ }^{3}$ and Full Collusion ${ }^{4}$. Compared to Kamien et al. (1992) which claim that the R\&D investment by firms engaged in Semi-collusion in R\&D is unambiguously greater than that in the Full Competition regime irrespective of spillovers, we demonstrate in fact which regime generates more R\&D effort in equilibrium depends upon both

\footnotetext{
1 The greater the distance between firms, the more differentiated the firms' products, the less the R\&D spillover.

2 It is also called "Production Cartel", see Brod and Shivakumar (1999).

3 R\&D Cartel.

4 The Full Collusion regime could also be considered as horizontal merger.
} 
the degree of product differentiation and the extent of technological distance. If we restrict our attention to the concave relationship, Full Collusion participants spend most on R\&D, and Semi-collusion participants spend more than firms in the Full Competition regime. This ranking of $\mathrm{R} \& \mathrm{D}$ efforts is unalterable and independent of the product differentiation, and the competition at the upstream stage depresses R\&D investment. Firms colluding in R\&D regardless of their production strategy always yield more profit and generate higher social welfare than firms colluding in output independently of R\&D strategy. When products are close substitutes, the synergy effects prevail over the anti-competitive effects due to the high spillovers, Full Collusion becomes a welfare-enhancing regime. Focusing on the convex relationship, $R \& D$ cooperation may reduce firms' interest to invest in $R \& D$, and it is possible that firms in the Full Collusion regime produce most and generate the highest level of social welfare. Furthermore, horizontal mergers might be interpreted as a Full Collusion where the participants coordinate their decisions with respect to all of strategic variables. Thus, we launch the discussion about antitrust policy, and shed light on the leniency of the total welfare standard and the restrictiveness of the consumer welfare standard.

The rest of this paper is organized as follows. Section 2 presents the model and solves the SPNE in the four alternative regimes. We compare R\&D effort, profit, consumer surplus and social welfare according to firms' behavior (competitive or collusive) in Sect. 3. Section 4 concludes this paper.

\section{The model}

\subsection{Hypothesis}

Consider an industry with two firms producing imperfectly substitutable goods. The representative consumer has a quasi-linear utility function

$$
U\left(q_{i}, q_{j}\right)=a\left(q_{i}+q_{j}\right)-\frac{1}{2}\left(q_{i}^{2}+q_{j}^{2}+2 \gamma q_{i} q_{j}\right)
$$

where " $q_{i}$ " is the output of firm $i$; " $a$ " is a constant which is assumed to be sufficiently large so that all firms product positive amounts in equilibrium; " $\gamma$ " measures the substitutability ${ }^{5}$ between the products and $\gamma \in[0,1)$. The utility function generates the following inverse demand function faced by firm $i$ :

$$
p_{i}\left(q_{i}, q_{j}\right)=a-q_{i}-\gamma q_{j}
$$

The production technology exhibits a constant marginal cost " $c$ " which can be reduced by investing in $R \& D$. Due to spillovers $(\beta)$, the $R \& D$ effort not only leads to a decrease in its own marginal cost, but also reduces the marginal cost of the rival

\footnotetext{
5 If $\gamma=0$, firms' products are not substitutable and each firm acts as a monopolist. Note that, when products are perfect substitutes, the spillover obviously equals to 1 and the game cannot be solved. See D’Aspremont and Jacquemin (1988).
} 
firm. Given the R\&D effort $x_{j}$ of firm $j(j=1,2$ and $i \neq j)$, firm $i$ 's effective marginal cost is

$$
C_{i}\left(x_{i}, x_{j}\right)=c-x_{i}-\beta x_{j}
$$

The $\mathrm{R} \& \mathrm{D}$ cost is assumed to be quadratic $\left(\frac{1}{2} x_{i}^{2}\right)$, which reflects the decreasing returns to $\mathrm{R} \& \mathrm{D}$ effort.

The individual profit of firm $i$ is defined by

$$
\pi_{i}=\left(p_{i}\left(q_{i}, q_{j}\right)-C_{i}\left(x_{i}, x_{j}\right)\right) q_{i}-\frac{1}{2} x_{i}^{2} \quad \text { with } i \neq j ; i, j=1,2
$$

The social welfare is the sum of producer surplus (denoted by $P S$ ) and consumer surplus (denoted by $C S$ ):

$$
W=P S+C S \quad \text { with } P S=\pi_{i}+\pi_{j}, C S=U-p_{i} q_{i}-p_{j} q_{j}
$$

The key feature of the model is to consider that the extent of product substitutability $(\gamma)$ determines the ability of a firm to appropriate its rival' R\&D effort. When products are less differentiated, competing firms share closer technological spaces, and one firm can benefit more from the rival's effort. We assume that the relationship between the spillover parameter $(\beta)$ and the degree of product differentiation $(\gamma)$ is described by:

$$
\beta(\gamma, h)=\gamma^{h} \quad \text { with } h \in\left[\frac{1}{2}, \frac{3}{2}\right], \gamma \in[0,1)
$$

where the parameter " $h$ " determines both the sensibility of the R\&D spillover to the degree of product differentiation, in other words, the measure of technological distance $^{6}$, and the level of spillovers for a given value of differentiation (see Fig. 1). The assumption $h \in\left[\frac{1}{2}, \frac{3}{2}\right]$ is necessary to guarantee the equilibrium existence in the four alternative scenarios. The range of $h$ permits us to touch upon the issue of concavity (technological proximity, $h<1$ ) and convexity (technological alienation, $h>1$ ). As $\frac{\partial \beta}{\partial \gamma}>0$ and $\frac{\partial \beta}{\partial h}<0$, we incur that, for any given value of $\gamma$, the concave relationship implies a more important spillover effect than the convex relationship. From the perspective of technological distance, the concavity refers to the situations where firms adopt similar technologies. Under concavity condition, the more differentiated are the products (close to 0 ), $R \& D$ spillovers are more sensitive to $\gamma$. One can imagine that the concavity $(h<1)$ corresponds to industries that are geographically concentrated and that rely upon sources of basic scientific knowledge or general purpose technologies (GPT) in the cluster ${ }^{7}$ benefit most from the exchange of knowledge and technology. By contrast, under convexity condition, the less differentiated are products (close to 1), the more sensitive R\&D spillovers with respect to $\gamma$, and the convexity delineates the situations where firms adopt different technologies.

\footnotetext{
${ }^{6}$ From the perspective of technological distance, it is straightforward that the more technologies are similar, the greater are spillovers, for a given level of product differentiation.

7 See more in Audretsch and Feldman (1996), Baptista and Swann (1998).
} 


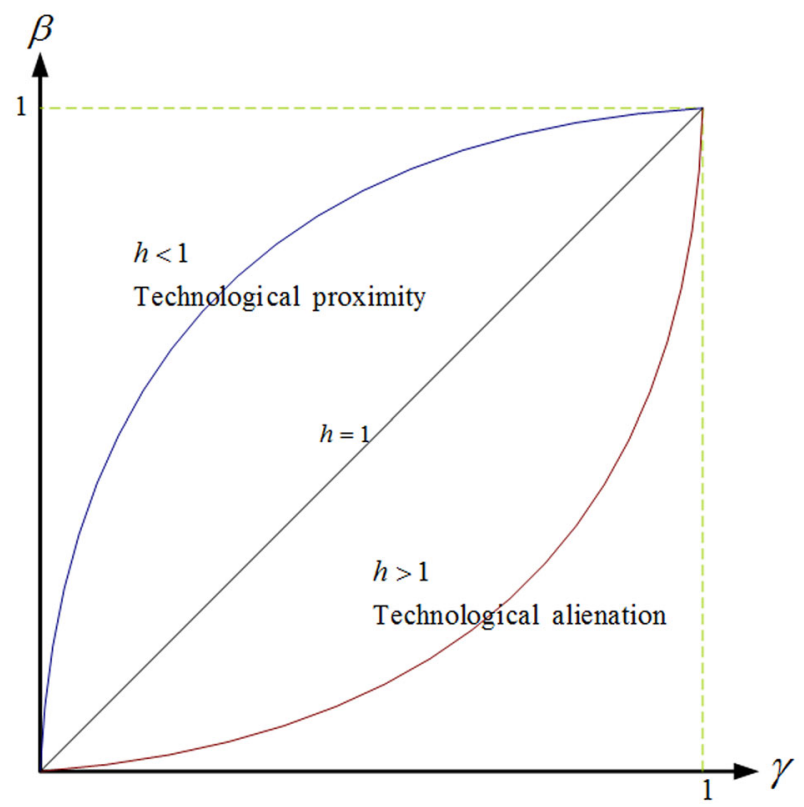

Fig. 1 R\&D spillovers and product differentiation. Source own graphic

We consider a two-stage game where firms act simultaneously at each stage. Firms select a strategic action (R\&D effort) at the first stage anticipating correctly its impact at the second stage. The two competing firms can either coordinate their decisions or adopt non-cooperative strategy at each stage. When firms collude in one dimension (R\&D or production) and compete in another one, such behavior is called semi-collusion (Fershtman and Gandal 1994). We compare the SPNE emerging in the four alternative scenarios (Table 1) such as Full Competition, Semicollusion in Production, Semi-collusion in R\&D and Full Collusion.

\subsection{Sub-game equilibrium in the four regimes}

\subsubsection{Full competition}

We begin with regime $F$, where there is no cooperation in any of the stages. The SPNE is obtained by backward induction. Firm $i$ chooses output $q_{i}$ to maximize individual profit $\pi_{i}$, and the firm $i$ 's output as a function of R\&D efforts is given by:

$$
q_{i}^{F}\left(x_{i}^{F}, x_{j}^{F}\right)=\frac{A(2-\gamma)+\left(2-\gamma^{h+1}\right) x_{i}^{F}+\left(2 \gamma^{h}-\gamma\right) x_{j}^{F}}{4-\gamma^{2}} \quad \text { with } A=a-c>0
$$

The sign of the derivative $\frac{\partial q_{i}^{F}\left(x_{i}^{F}, x_{j}^{F}\right)}{\partial x_{i}^{F}}$ is unambiguously positive, it demonstrates that the output of firm $i$ increases with its own R\&D effort. By contrast, concerning the sign of $\frac{\partial q_{i}^{F}\left(x_{i}^{F}, x_{j}^{F}\right)}{\partial x_{j}^{F}}$, we have 
Table 1 Four alternative scenarios. Source own table

\begin{tabular}{|c|c|c|}
\hline $\begin{array}{l}\text { Four alternative } \\
\text { scenarios }\end{array}$ & First stage $(\mathrm{R} \& \mathrm{D})$ & Seconde stage (production) \\
\hline $\begin{array}{l}\text { Full competition } \\
\quad \text { (regime } \mathbf{F})\end{array}$ & $\begin{array}{l}\text { Firms compete in } R \& D \text {; each firm } \\
\text { decides its own R\&D level given R\&D } \\
\text { efforts of the other firm }\end{array}$ & $\begin{array}{l}\text { Firms compete; each firm decides } \\
\text { its own output to maximize the } \\
\text { individual profit }\end{array}$ \\
\hline $\begin{array}{l}\text { Semi-collusion in } \\
\text { Production } \\
\text { (Production Cartel) } \\
\text { (regime P) }\end{array}$ & $\begin{array}{l}\text { Firms compete in } R \& D \text {; each firm } \\
\text { decides its own R\&D level given R\&D } \\
\text { efforts of the other firm }\end{array}$ & $\begin{array}{l}\text { Firms coordinate their production } \\
\text { activities to maximize the joint } \\
\text { profit }\end{array}$ \\
\hline $\begin{array}{l}\text { Semi-collusion in R\&D } \\
\text { (R\&D Cartel) (regime } \\
\text { R) }\end{array}$ & $\begin{array}{l}\text { Firms coordinate their R\&D activities to } \\
\text { maximize the joint profit; cooperative } \\
\text { behavior in } R \& D \text { does not change the } \\
\text { level of spillovers }\end{array}$ & $\begin{array}{l}\text { Firms compete; each firm decides } \\
\text { its own output to maximize the } \\
\text { individual profit }\end{array}$ \\
\hline $\begin{array}{l}\text { Full collusion } \\
\text { (Horizontal Merger) } \\
\text { (regime } \mathbf{M})\end{array}$ & $\begin{array}{l}\text { Firms coordinate their R\&D activities to } \\
\text { maximize the joint profit; cooperative } \\
\text { behavior in } R \& D \text { does not change the } \\
\text { level of spillovers }\end{array}$ & $\begin{array}{l}\text { Firms coordinate their production } \\
\text { activities to maximize the joint } \\
\text { profit }\end{array}$ \\
\hline
\end{tabular}

- $\frac{\partial q_{i}^{F}\left(x_{i}^{F}, x_{j}^{F}\right)}{\partial x_{j}^{F}}<0$, if $h>1+\frac{\log \left(\frac{1}{2}\right)}{\log \gamma}$

- $\frac{\partial q_{i}^{F}\left(x_{i}^{F}, x_{j}^{F}\right)}{\partial x_{j}^{F}}>0$, otherwise

When the technological distance is large enough $\left(h>1+\frac{\log \left(\frac{1}{2}\right)}{\log \gamma}\right)$, the technologies adopted by firms are very different, one firm's production will be negatively affected by its rival's R\&D investment. By substituting Eq. (7) into the profit function Eq. (4), we can rewrite the profit function as $\pi_{i}^{F}\left(x_{i}^{F}, x_{j}^{F}\right)$. In the first stage, each firm chooses R\&D effort independently to maximize the individual profit. The SPNE of per-firm R\&D effort, output, profit and social welfare is given by:

$$
\begin{gathered}
x^{F}=\frac{2 A\left(2-\gamma^{h+1}\right)}{\Psi_{F}}, \quad q^{F}=\frac{A(2-\gamma)(2+\gamma)}{\Psi_{F}} \\
\pi^{F}=\frac{A^{2} \Xi_{F}}{\Psi_{F}^{2}}, \quad W^{F}=\frac{A^{2} \Omega_{F}}{\Psi_{F}^{2}}
\end{gathered}
$$

with

$$
\begin{aligned}
& \Psi_{F}=\left(4 \gamma+8-\gamma^{3}-2 \gamma^{2}\right)+2\left(\gamma^{2 h+1}+\gamma^{h+1}-2 \gamma^{h}-2\right)>0 \\
& \Xi_{F}=\left(\gamma^{2}-4\right)^{2}-2\left(\gamma^{h+1}-2\right)^{2}>0 \\
& \Omega_{F}=\left(48+16 \gamma-24 \gamma^{2}-8 \gamma^{3}+3 \gamma^{4}+\gamma^{5}\right)-4\left(\gamma^{h+1}-2\right)^{2}>0
\end{aligned}
$$




\subsubsection{Semi-collusion in production}

Semi-collusion in Production is denoted by $P$, firms choose their R\&D efforts noncooperatively, but select their outputs cooperatively. Firm $i$ 's output, as a function of R\&D effort, can be expressed as:

$$
q_{i}^{P}\left(x_{i}^{P}, x_{j}^{P}\right)=\frac{A(1-\gamma)+\left(1-\gamma^{h+1}\right) x_{i}^{P}+\left(\gamma^{h}-\gamma\right) x_{j}^{P}}{2\left(1-\gamma^{2}\right)}
$$

The derivative $\frac{\partial q_{i}^{P}\left(x_{i}^{P}, x_{j}^{P}\right)}{\partial x_{i}^{P}}$ is always positive, and $\frac{\partial q_{i}^{P}\left(x_{i}^{P}, x_{j}^{P}\right)}{\partial x_{j}^{P}}$ is positive when $h<1$ (concave relationship); negative while $h>1$ (convex relationship).

The SPNE:

$$
\begin{gathered}
x^{P}=\frac{A\left(2-\gamma^{h+1}-\gamma\right)}{\Psi_{P}}, \quad q^{P}=\frac{2 A(1-\gamma)}{\Psi_{P}} \\
\pi^{P}=\frac{A^{2} \Xi_{P}}{2 \Psi_{P}^{2}}, \quad W^{P}=\frac{A^{2} \Omega_{P}}{\Psi_{P}^{2}}
\end{gathered}
$$

with

$$
\begin{aligned}
& \Psi_{P}=4\left(1-\gamma^{2}\right)+\gamma^{h}\left(2 \gamma+\gamma^{h+1}-2\right)+\gamma-2>0 \\
& \Xi_{P}=8\left(\gamma^{3}-\gamma^{2}-\gamma+1\right)-\left(\gamma^{h+1}-2\right)^{2}+4 \gamma-\gamma^{2}-2 \gamma^{h+2}>0 \\
& \Omega_{P}=12\left(\gamma^{3}-\gamma^{2}-\gamma+1\right)-\left(\gamma^{h+1}-2\right)^{2}+4 \gamma-\gamma^{2}-2 \gamma^{h+2}>0
\end{aligned}
$$

\subsubsection{Semi-collusion in $R \& D$}

Firms coordinate their $R \& D$ investment in the $R \& D$ stage, and then maintain competition in the production stage. This regime is abbreviated by $R$

$$
\begin{gathered}
x^{R}=\frac{2 A\left(1+\gamma^{h}\right)}{\Psi_{R}}, \quad q^{R}=\frac{A(2+\gamma)}{\Psi_{R}} \\
\pi^{R}=\frac{A^{2}}{\Psi_{R}}, \quad W^{R}=\frac{A^{2} \Omega_{R}}{\Psi_{R}^{3}}
\end{gathered}
$$

with

$$
\begin{aligned}
\Psi_{R}= & (\gamma+2)^{2}-2\left(\gamma^{h}+1\right)^{2}>0 \\
\Omega_{R}= & \left(\gamma^{5}+11 \gamma^{4}+46 \gamma^{3}+86 \gamma^{2}+64 \gamma+16\right)+8\left(\gamma^{4 h}+4 \gamma^{3 h}+6 \gamma^{2 h}+4 \gamma^{h}\right) \\
& -\left(40 \gamma^{2 h}+80 \gamma^{h}+2 \gamma^{2 h+3}+96 \gamma^{h+1}+48 \gamma^{2 h+1}+36 \gamma^{h+2}+18 \gamma^{2 h+2}+4 \gamma^{h+3}\right) \\
& >0
\end{aligned}
$$




\subsubsection{Full collusion (horizontal merger)}

Despite the ostensibly widespread use of Full Collusion to exploit the complementarities in firm's R\&D process, the formal literature on R\&D has almost focus exclusively on research joint venture, whereby firms share out technological knowledge $(\beta=1)$ while continuing to compete against each other in product market (see Kamien et al. 1992). ${ }^{8}$ Here, we regard this scenario as the framework of multi-dimensional coordination in which firms cooperate in both $R \& D$ and production stages. Since, the products are imperfectly substitutable, Full Collusion ${ }^{9}$ means that the firms maximize their joint profit in each stage.

The SPNE of R\&D effort, output, profit and welfare is given by

$$
\begin{gathered}
x^{M}=\frac{A\left(1+\gamma^{h}\right)}{\Psi_{M}}, \quad q^{M}=\frac{A}{\Psi_{M}} \\
\pi^{M}=\frac{A^{2}}{2 \Psi_{M}^{2}}, \quad W^{M}=\frac{A^{2} \Omega_{M}}{\Psi_{M}^{2}}
\end{gathered}
$$

with

$$
\begin{aligned}
& \Psi_{M}=2(1+\gamma)-\left(\gamma^{h}+1\right)^{2}>0 \\
& \Omega_{M}=3(1+\gamma)-\left(\gamma^{h}+1\right)^{2}=\Psi_{M}+(1+\gamma)>0
\end{aligned}
$$

In the following section, we will compare these four aforementioned regimes in terms of significative relevance such as $R \& D$ investment, profit, consumer surplus and social welfare.

\section{Comparison of different regimes}

\subsection{R\&D effort}

We start with the comparison of R\&D investment level and address the question: which regime generates the highest level of $R \& D$ effort in equilibrium? To compare individual levels of R\&D under different regimes, let us define the functions $f_{k}(\gamma, h)$, $g_{k}(\gamma, h)$ and $j_{F}(\gamma, h)$

\footnotetext{
${ }^{8}$ Kamien et al. (1992) provide a thorough analysis of RJV, contrasting the case of RJV Competition where firms pool R\&D results, but behave non-cooperatively at both stages, and RJV Cartelization (the pooling of $R \& D$ results with cooperative determination of $R \& D$ investment, but competition in subsequent product market stage). Suzumura (1992) and Suzumura and Yanagawa (1993) contain a closely related analysis. D'Aspremont and Jacquemin (1988) do allow for merger under which firms pool $R \& D$ results and cooperate in both stage of the game. It is worth noting that there are the analysis of the converse case to RJV, where all firms compete in R\&D stage, but then collude in outputs, see Fershtman and Gandal (1994) and Brod and Shivakumar (1999).

${ }^{9}$ The Full Collusion regime could be considered as horizontal merger.
} 


$$
\begin{cases}f_{k}(\gamma, h)=x^{M}(\gamma, h)-x^{k}(\gamma, h) & \text { with } k=\{F, P, R\} \\ g_{k}(\gamma, h)=x^{R}(\gamma, h)-x^{k}(\gamma, h) & \text { with } k=\{F, P\} \\ j_{F}(\gamma, h)=x^{P}(\gamma, h)-x^{F}(\gamma, h) & \end{cases}
$$

We plot the curves $f_{k}(\gamma, h)=0, g_{k}(\gamma, h)=0, j_{F}(\gamma, h)=0$ in $\gamma$ and $h$ space and this pattern implies the ranking of R\&D efforts into five zones (Fig. 2).

\section{Result 1}

(i) When firms have same behavior in the upstream stage, the downstream cooperation can incite firms to exert more $R \& D$ investment.

(ii) When firms adopt different technologies and produce differentiated goods (cf. Fig. 2, green area), the firms colluding in production will invest most in $R \& D$.

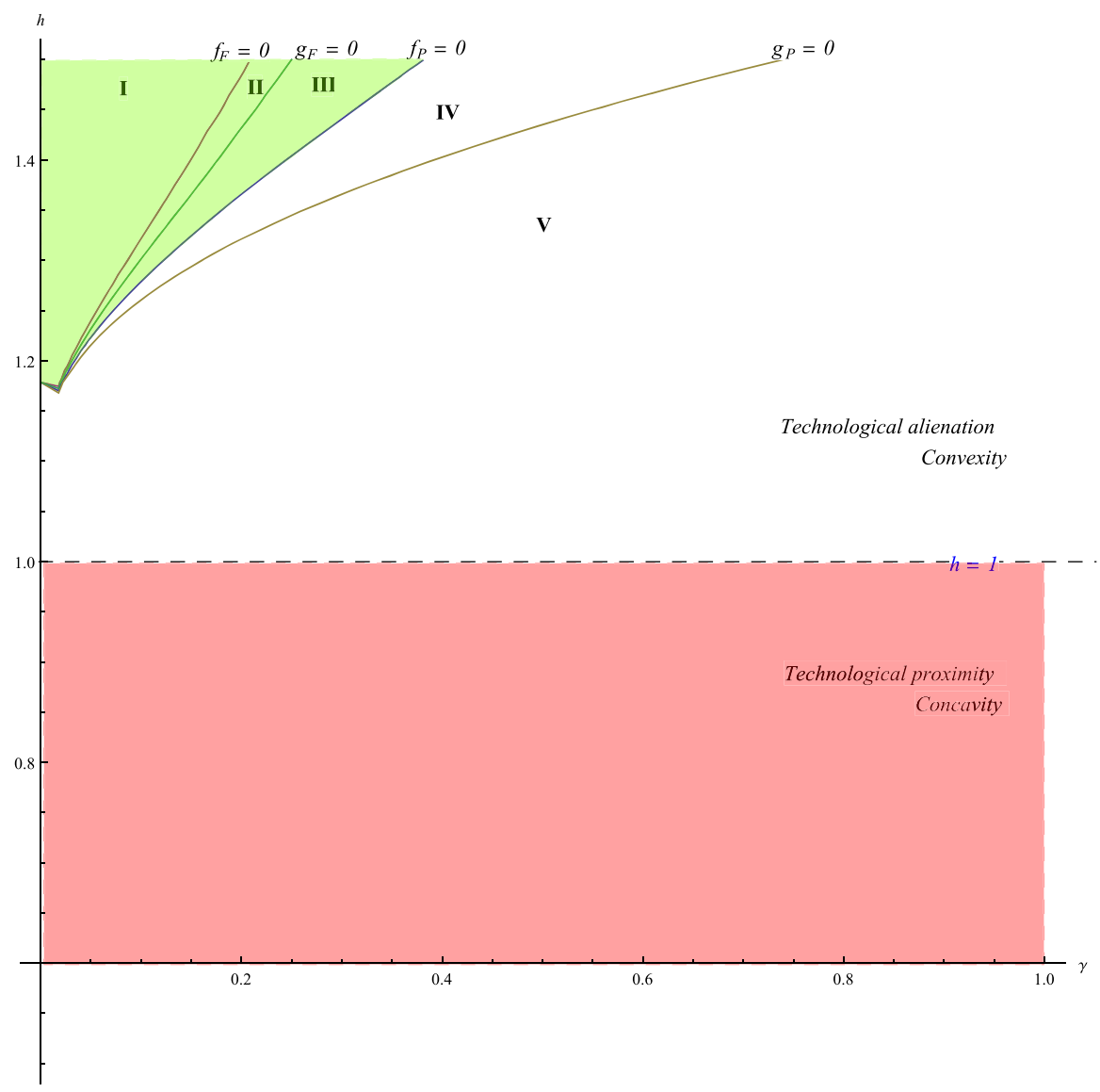

Fig. 2 R\&D investment ranking. Source own graphic 
(iii) Under technological proximity, firms with two-stage cooperation have most incentive to invest in $R \& D$ without ambiguity.

Proof Based on Fig. 2, the R\&D efforts (equilibrium) in the different regimes are arranged in the following form

- $x^{P}>x^{F}>x^{M}>x^{R}$ (zone $\left.I\right)$

- $x^{P}>x^{M}>x^{F}>x^{R}$ (zone II)

- $x^{P}>x^{M}>x^{R}>x^{F}$ (zone III)

- $x^{M}>x^{P}>x^{R}>x^{F}$ (zone IV)

- $x^{M}>x^{R}>x^{P}>x^{F}$ (zone $V$ )

First of all, we find when firms have same behavior (cooperation or competition) in the upstream R\&D stage, firms allowed to cooperate in the product market always exert more R\&D efforts in equilibrium, compared to firms competing in the downstream stage $\left(x^{M}>x^{R}\right.$ and $\left.x^{P}>x^{F} \forall \gamma, h\right)$. As we know, R\&D efforts reduce the marginal cost and indirectly lead to a decrease of the product price. When firms can collude in the downstream stage, they restrict their outputs for a given R\&D effort and as a consequence, the negative impact of $R \& D$ efforts on the product price is alleviated. Conversely, an intense product competition dissipates the benefits of $R \& D$ effort and, therefore, shrinks the incentive to invest in R\&D. The output cooperation has a positive impact on $R \& D$ investment and then induces firms to undertake more $\mathrm{R} \& \mathrm{D}$ than they would under competition in the downstream stage.

The output cooperation reinforces the $R \& D$ effort for a given behavior at upstream stage. However, when the behavior at downstream stage is given, the $\mathrm{R} \& \mathrm{D}$ cooperation does not unambiguously increase research efforts. If we compare the regime $F$ with the regime $R$ (corresponding, respectively, to the lowest level in terms of $R \& D$ effort), it is found that $R \& D$ cooperation could be detrimental to $\mathrm{R} \& \mathrm{D}$ effort in zone I and zone II. This finding is in sharp contrast with the existing literature, for instance, Kamien et al. (1992) show that $x^{R}$ is unambiguously greater than $x^{F}$ without taking into account the close relationship emphasized in this paper.

The striking outcome we find here is that R\&D investment under regime $P$ can be the largest (cf. Fig. 2, green area). It is different from the conventional wisdom that merged (two-stage cooperation) firms have more incentive to invest in R\&D, because they appropriate all of the R\&D efforts. The spillover effect (in zones I,II and $I I I)$ constitutes a positive, but very small externality. When firms cooperate in the upstream stage (regimes $M, R$ ), on the one hand this small externality is internalized, on the other hand the R\&D cooperation cannot promote the spending on common research of firms due to technological alienation (convexity). However, Semi-collusion in Production can intensify the R\&D competition by production cooperation, and incites firms to invest more in R\&D. Therefore, the regime $P$ leads to the highest level of $\mathrm{R} \& \mathrm{D}$ effort in green area. Moreover, if we restrict our 
attention to the case where the relationship between product differentiation and $\mathrm{R} \& \mathrm{D}$ spillover is concave (red area), the ranking of $\mathrm{R} \& \mathrm{D}$ efforts $\left(x^{M}>x^{R}>x^{P}>x^{F}\right)$ does not alter, and it is independent of the product differentiation. It means that the Full Collusion participants spend more on R\&D than Semi-collusion ones, under concave relationship (technological proximity).

From the aggregate surplus point of view, the welfare performance of $R \& D$ investment in the different scenarios can be gauged, and we compare them with the First-Best welfare criterion (Suzumura 1992). "Appendix 1" provides the proof of the expression $x^{\mathrm{FB}}$.

$$
x^{\mathrm{FB}}=\frac{A\left(1+\gamma^{h}\right)}{(1+\gamma)-\left(1+\gamma^{h}\right)^{2}}
$$

Obviously, $x^{\mathrm{FB}}$ is the significant standard accessing whether the $\mathrm{R} \& \mathrm{D}$ investment is efficient, when the denominator $(1+\gamma)-\left(1+\gamma^{h}\right)^{2}$ is positive.

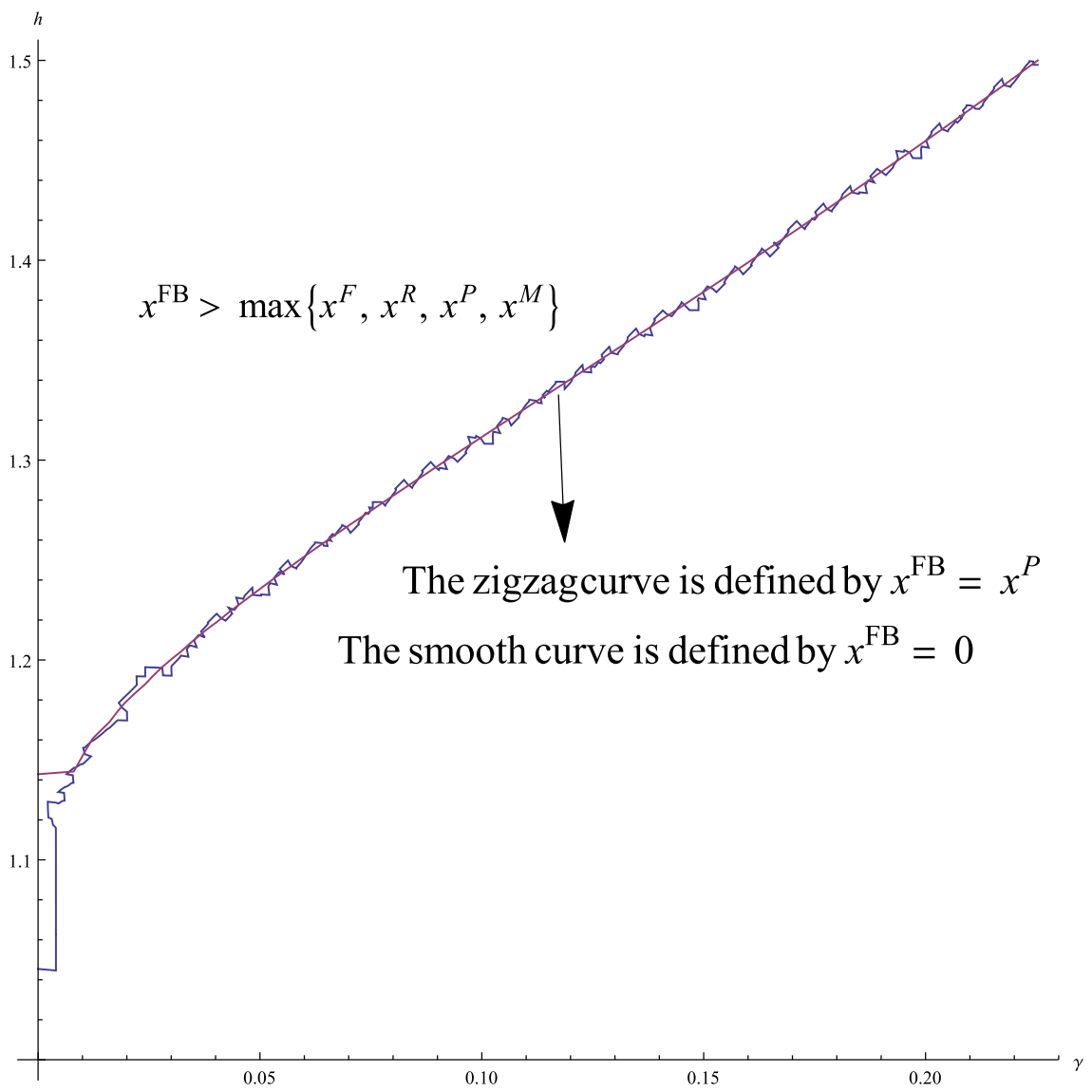

Fig. 3 Socially first-best R\&D. Source own graphic 
In Fig. 3, we plot the curves in $\gamma \in\left[0, \frac{1}{4}\right]$ and $h \in\left[1, \frac{3}{2}\right]$ space to zoom and emphasize the area $x^{\mathrm{FB}}>\max \left\{x^{F}, x^{R}, x^{P}, x^{M}\right\}$. The smooth curve $x^{\mathrm{FB}}=0$ divides the pattern into two parts and the left one represents $x^{\mathrm{FB}}>0$. The intersection area between the smooth curve and the zigzag curve $\left(x^{\mathrm{FB}}=x^{P}\right)$ defines combinations of $\gamma$ and $h$ where $x^{P}>x^{\mathrm{FB}}$. D'Aspremont and Jacquemin (1988) and Henriques (1990) show that the social optimum R\&D effort was unambiguously greater than the level of R\&D investment in equilibrium under the fully cooperative or non-cooperative or mixed $^{10}$ game. Compared to them, we find the similar result when firms produce sufficiently heterogeneous goods. Furthermore, it is worthwhile to note $x^{P}$ can be higher than $x^{\mathrm{FB}}$ in an infinitesimal area where a higher level of $\mathrm{R} \& \mathrm{D}$ effort corresponds to a wasteful duplication.

\subsection{Output and consumer surplus}

Due to symmetric equilibria, output is considered as an index of consumer surplus $\left(\mathrm{CS}^{k}=(1+\gamma)\left(q^{k}\right)^{2}\right.$ with $\left.k=\{F, P, R, M\}\right)$. We trace out the meaningful areas by plotting the following curves:

$$
\left\{\begin{array}{l}
R_{k}(\gamma, h)=q^{M}(\gamma, h)-q^{k}(\gamma, h) \quad \text { with } k=\{F, P, R\} \\
V_{k}(\gamma, h)=q^{R}(\gamma, h)-q^{k}(\gamma, h) \quad \text { with } k=\{F, P\} \\
Z_{F}(\gamma, h)=q^{P}(\gamma, h)-q^{F}(\gamma, h)
\end{array}\right.
$$

\section{Result 2}

(i) The level of output and consumer welfare in fully cooperative scenario can be higher (cf. Fig. 4, green area) than that in partially cooperative or fully non-cooperative situations.

(ii) When firms adopt similar technologies (concavity), $R \& D$ cooperation (regimes $M$ and $R$ ) encourages firms to produce more, and leads to fierce output competition.

(iii) Firms under Full Competition can produce most and achieve the highest level of consumer welfare (red area), if and only if they use very different technologies and produce highly differentiated goods.

Proof Based on Fig. 4, the individual output equilibrium in the different regimes is arranged in the following form

- $q^{F}>q^{R}>q^{P}>q^{M}$ (zone I)

- $q^{R}>q^{F}>q^{P}>q^{M}$ (zone II)

- $q^{R}>q^{F}>q^{M}>q^{P}$ (zone III)

- $q^{R}>q^{M}>q^{F}>q^{P}$ (zone IV)

\footnotetext{
${ }^{10}$ Firms cooperate in R\&D, but remain non-cooperative in output. This game corresponds to the Semicollusion in R\&D within our framework.
} 


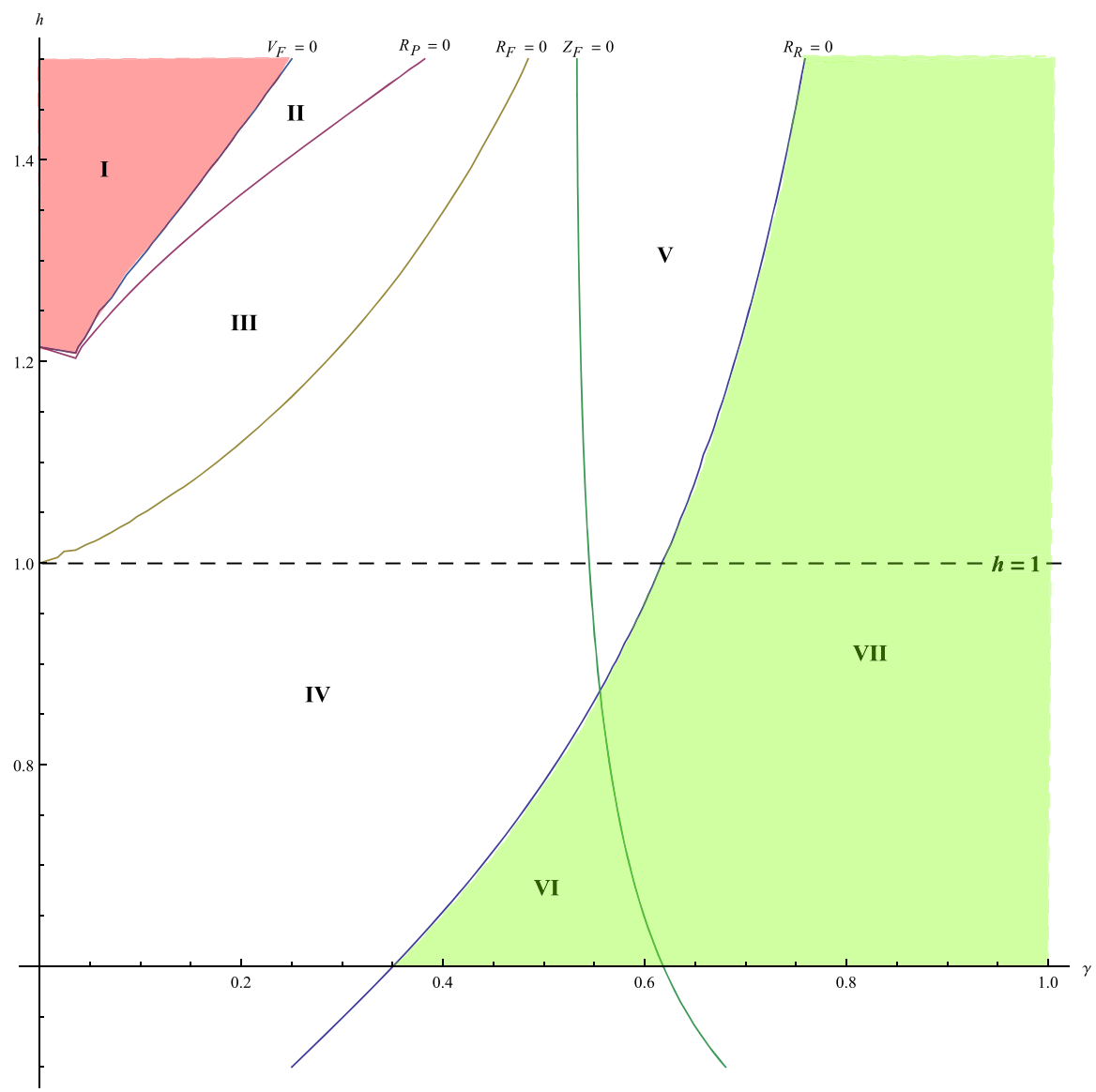

Fig. 4 The output (consumer surplus) ranking. Source own graphic

- $q^{R}>q^{M}>q^{P}>q^{F}$ (zone $V$ )

- $q^{M}>q^{R}>q^{F}>q^{P}$ (zone VI)

- $q^{M}>q^{R}>q^{P}>q^{F}$ (zone VII)

Apart from Semi-collusion in Production, each regime can yield the highest level of output (consumer surplus) for plausible parameter combinations. When firms produce sufficiently similar goods, the Full Collusion regime ensures the highest level (green area). This finding is in contrast with the traditional literature "the firms under Full Competition always produce more than the firms under Full Collusion scenarios" ${ }^{\prime 1}$. The reason behind this is the substitutability-spillover relationship:

\footnotetext{
${ }^{11}$ D'Aspremont and Jacquemin (1988) and Henriques (1990) demonstrate the level of output in noncooperative two-stage case is always higher than that in fully cooperative situation. In addition, they claim that the mixed game can generate more output than non-cooperative two-stage game for large spillovers. These models based on the assumption of homogenous goods.
} 
the low level of differentiation on the one hand generates the high level of spillovers, on the other hand, it induces firms under Full Collusion to spend more on R\&D (Result 1), accordingly the marginal cost of Full Collusion participants is sufficiently reduced, firms under Full Collusion have interest to expand their output. We also find that the output level is the highest in the regime $R$ when the goods are sufficiently differentiated (zones II,III,IV,V). Furthermore, if the sensibility parameter $h$ is comparatively large (technological alienation), Full Competition generates the highest output level (zone I). The reason of the instable relationship between $q^{R}$ and $q^{M}$ arises from the sensibility of output to R\&D effort: in the symmetric equilibria, the sensibility under regime $R$ and $M$ is, respectively, given by

$$
\begin{gathered}
\frac{\partial q^{R}}{\partial x^{R}}=\frac{2-\gamma^{h+1}+2 \gamma^{h}-\gamma}{4-\gamma^{2}}>0 \\
\frac{\partial q^{M}}{\partial x^{M}}=\frac{1-\gamma^{h+1}+\gamma^{h}-\gamma}{2\left(1-\gamma^{2}\right)}>0
\end{gathered}
$$

It is found that $\frac{\partial q^{R}}{\partial x^{R}}>\frac{\partial q^{M}}{\partial x^{M}}$, this inequality discloses that the output in the regime $R$ is more sensitive to R\&D effort compared to the one in the regime $M$. In addition, $x^{M}>x^{R}$ holds true at all time (Result 1). Indeed, $q^{M}$ can be greater than $q^{R}$ in some zones (VI and VII).

There is no stable hierarchy because the impact of R\&D effort is complicated and exerts two conflicting effects on the output of rival firm. On the one hand, R\&D effort is managed to induce the firm to expand output at expense of its rival by cutting down its own production cost. It is considered as the substitutability effect (an increase in its own output leads to a decrease in rival's output) which is greater, the more substitutable the products are. On the other hand, the R\&D effort can reduce the rival firm's cost, thereby increase its rival firm's output. It is regarded as the spillover effect (boosting rival's output) which is greater the larger the spillover is. Since the spillover depends positively on the degree of product differentiation, when products are quasi homogeneous, both substitutability effect and spillover effect enlarge. Whether the output (consumer surplus) increases depends on the interplay of these two conflicting effects. If the spillover effect prevails over the substitutability effect, firms are motivated to expand output; otherwise, they prefer to shrink output.

According to Fig. 4, it is clear that firms colluding in R\&D produce more than firms competing on $\mathrm{R} \& \mathrm{D}\left(q^{R}, q^{M}>q^{P}, q^{F}\right)$ when the relationship between substitutability and spillover is concave $(h<1)$. This result holds always true regardless of product differentiation. Under the circumstance that the leakage of know-how is relatively strong (concave relationship), firms cooperating on $R \& D$ are willing to spend more on R\&D efforts (Result 1), the marginal costs of both firms are reduced so much that the spillover effect prevails over the substitutability effect, and firms are motivated to expand output. The curve $V_{F}=0$ is a watershed of the relationship between $q^{R}$ and $q^{F}$ which is consistent with the corollary shown in Kamien et al. (1992) ${ }^{12}$.

\footnotetext{
${ }^{12}$ They demonstrate the price (output) in R\&D cartelization is less (more) than the price in $R \& D$ competition if and only if $\gamma \leq 2 \beta$.
} 
The relationship $q^{R}>q^{P}$ holds true for all $\gamma$ and $h$. The intuition behind this stems from the variation of competition intensity ${ }^{13}$. Under regime $R$, upstream collusion leads to much more fierce rivalry in non-cooperative output stage. Furthermore, since firms collude in output under regime $P$, the market becomes looser, and the firms have more incentives to increase the price by reducing output.

We find also that the firms colluding in output produce less than the firms competing in production market when the goods are sufficiently differentiated (zones I, II, III). First, the downstream output cooperation induces firms to increase the price and decrease the output; second, as the low value for $\gamma$ generates the small spillovers, the R\&D efforts exerted by firm $i$ cannot sufficiently reduce its rival 's marginal cost, this spillover effect is not strong enough to compensate the decrease in output due to production cooperation, therefore, firms have to shrink output.

\subsection{Profit}

According to Brod and Shivakumar (1999) ${ }^{14}$ (henceforth, "BS"), the profit under Full Competition could be greater than under Semi-collusion in Production in some cases. When there is the "close relationship" between product differentiation and R\&D spillovers, we have the following result:

\section{Result 3}

The firms in Full Collusion are most profitable while the firms in Full Competition are least profitable.

(ii) When firms adopt similar technologies (concavity), they prefer taking part in $R \& D$ Cartel to joining in Production Cartel (cf. Fig. 5, red area).

(iii) When firms adopt different technologies (convexity), the firms in Production Cartel could generate more profit than that in $R \& D$ Cartel (cf. green area $\pi^{P}>\pi^{R}$ and white area $\pi^{P}<\pi^{R}$ ).

\footnotetext{
${ }^{13}$ See Fershtman and Gandal (1994).

${ }^{14}$ In an one-stage game, cartels increase industry profits and exacerbate the consumer surplus. In a model where firms collude in production, but compete in R\&D, the cartel members may be worse off and consumers better off due to over-investment by firms eager to improve their position in the cartel. Brod and Shivakumar (1999) analyze a two-stage model and examine the effect of semi-collusion when the non-production activity is R\&D. Firms choose their R\&D effort in a first stage and output in a second stage. They shed light on the fact that in the presence of spillovers, firms and consumers could be both better off, peradventure both worse off, by a semi-collusive production cartel. We are attired by this fascinating outcome. Thereupon, we try to approach the in-depth analysis and understand the driving forces of this result. We find, however, that the findings of Brod and Shivakumar (1999) are disputable. The incorrect SPNE values of per-firm R\&D effort, output and profit due to improper handling result in the inaccuracy of their main propositions. When the goods are sufficiently substitutable, the proposition 1 does not hold. In other words, there is no absolute predominance of production cartel in terms of R\&D effort. Since the optimum equilibrium of cartel at the production stage could be negative for certain combination parameters (the degree of product differentiation and the level of spillovers), we find the region D depicted as "Consumers prefer Production Cartel; firms prefer Competition" could not always satisfy the conditions mentioned in proposition 2. In "Appendix 2", we focus upon their calculative errors, and show what the correct solution can be.
} 


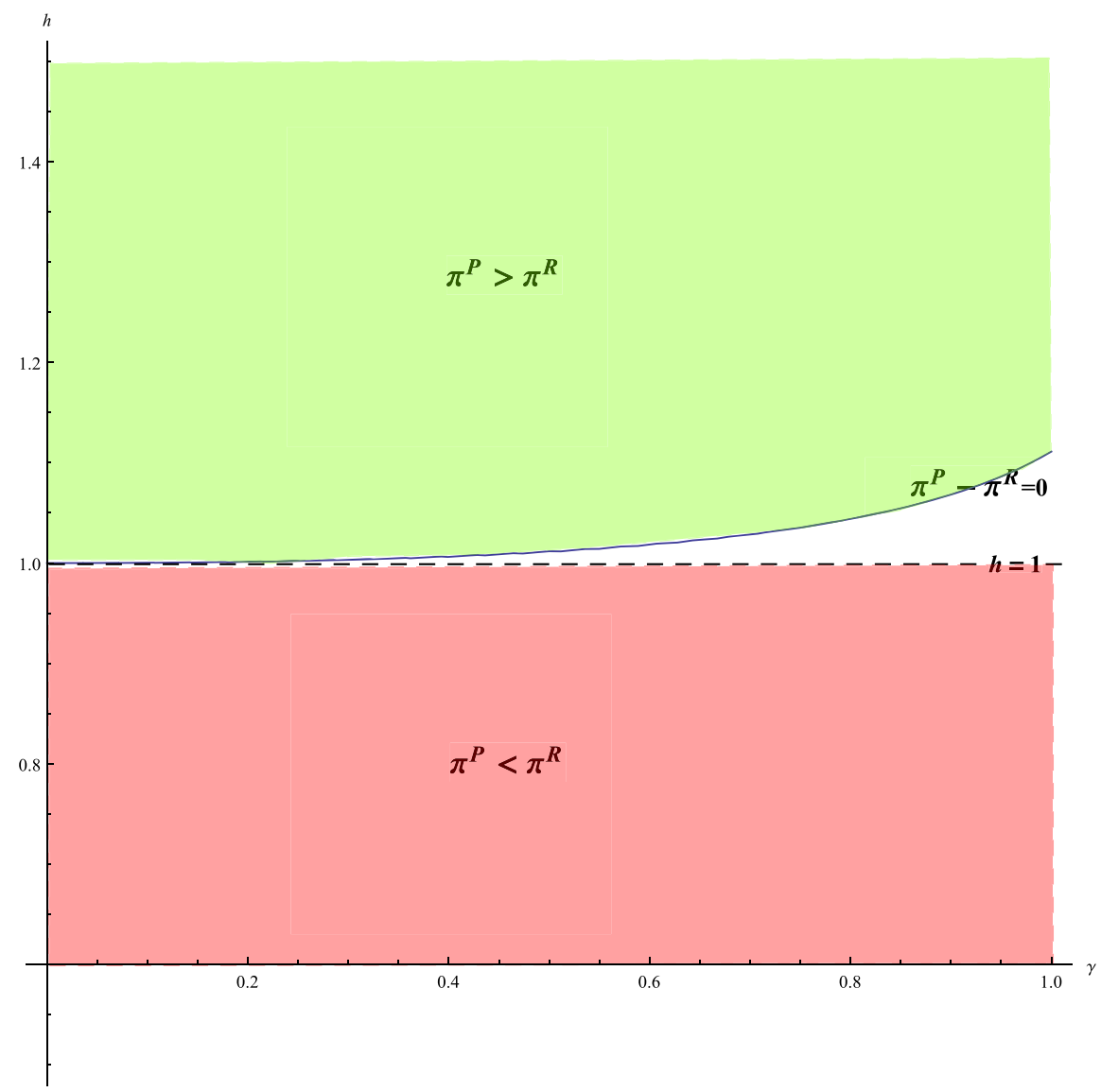

Fig. 5 Two types of semi-collusion. Source own graphic

Proof The equilibrium individual firm's profits are arranged:

$$
\begin{aligned}
& \pi^{M}>\max \left[\pi^{P}, \pi^{R}\right]>\min \left[\pi^{P}, \pi^{R}\right]>\pi^{F} \forall \gamma, h \\
& \pi^{M}>\pi^{R}>\pi^{P}>\pi^{F} \forall \gamma \quad \text { if } h<1
\end{aligned}
$$

When the spillover is relative to the product differentiation, the profit of the firms in the regime $P$ always prevails over the one in the regime $F$. This result is in contrast with Brod and Shivakumar (1999) which shows that the profit under regime $F$ could be higher than under regime $P$. Furthermore, in line with semi-collusion literature (Matsui 1989; Fershtman and Gandal 1994), we establish the possibility that R\&D Cartel is less profitable than Production Cartel.

We find that the profit of firms with fully cooperative behavior prevails over onedimension cooperation profit which is higher than the profit earned by the firm in Full Competition. It is only that the relationship between two types of semi- 
delegation can be altered. The alluring question is which type of semi-collusion (Production Cartel or R\&D Cartel) will be more beneficial for firms.

Consider $\Delta$ as the difference of profits in two semi-collusion scenarios:

$$
\Delta=\pi^{P}-\pi^{R}
$$

We examine the profit ranking with the same method used in the previous subsection. The result is illustrated in Fig. 5. The interesting conclusion which emerges from this figure is that both Semi-collusion in R\&D and Semi-collusion in Production can yield more profit.

Under concave relationship (technological proximity), firms colluding in R\&D generate always more profit than firms colluding in output. The intuition of this result is the following: compared to the regime $P$, the distinctive advantage of the regime $R$ is that firms invest more in $\mathrm{R} \& \mathrm{D}$ under concave relationship (See Result 1), thereby, firms are more competitive due to cost-saving by R\&D investment; furthermore, according to Result 2, firms in the regime $R$ produce more than firms in the regime $P$. Despite the fact that R\&D investment is expensive, the profit of the firms in the regime $R$ is still higher than that in the regime $P$ when $h<1$.

The inverse outcome $\pi^{P}>\pi^{R}$ can take place for some plausible $\gamma$ under convexity condition (technological alienation). In particular, when $h$ is approximately greater than the critical value which is equal to $1.12, \pi^{P}>\pi^{R}$ holds always true.

\subsection{Social welfare}

In general, the welfare is damaged by collusion: in one-stage game, the collusion always harms the welfare; whereas in two-stage game where firms first choose R\&D efforts, collusion reduces welfare if it occurs in each of the two stages ${ }^{15}$. We determine which regime is the most relevant with regard to aggregate surplus (Fig. 6).

\section{Result 4}

(i) Full Collusion can generate the highest level in social welfare, in particular when firms produce the similar goods (cf. Fig. 6, green area).

(ii) When firms produce the differentiated goods (red area), Semi-collusion in $R \& D$ enhances most the social welfare.

Proof Based on Fig. 6, the social welfare ranking will be:

- $W^{F}>W^{R}>W^{P}>W^{M}$ (zone $\left.I\right)$

- $W^{R}>W^{F}>W^{P}>W^{M}$ (zone II)

- $W^{R}>W^{F}>W^{M}>W^{P}$ (zone III)

- $W^{R}>W^{M}>W^{F}>W^{P}$ (zone IV)

${ }^{15}$ See D’Aspremont and Jacquemin (1988), Suzumura (1992). 


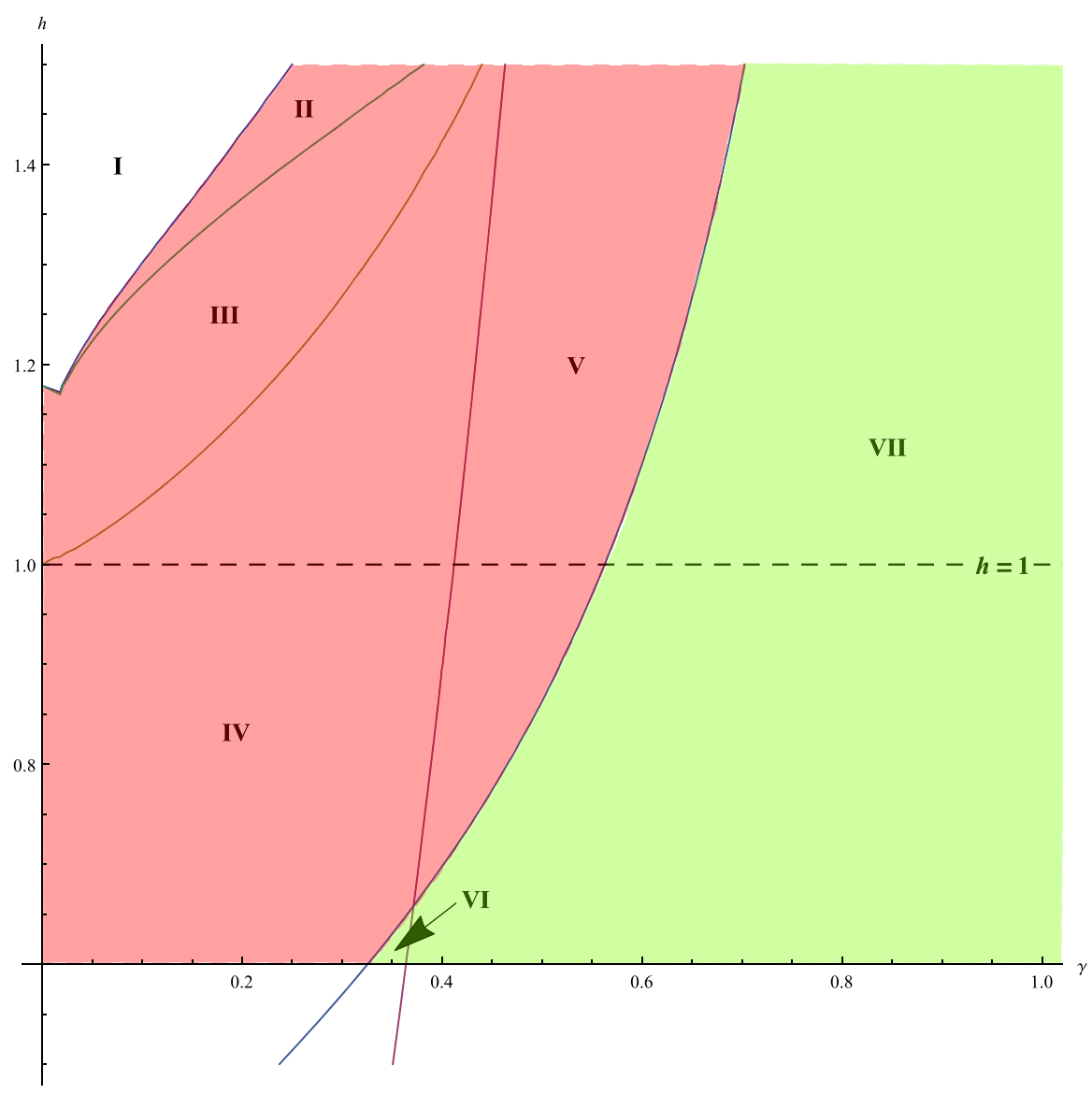

Fig. 6 The welfare ranking. Source own graphic

- $W^{R}>W^{M}>W^{P}>W^{F}$ (zone $V$ )

- $W^{M}>W^{R}>W^{F}>W^{P}$ (zone $V I$ )

- $W^{M}>W^{R}>W^{P}>W^{F}$ (zone VII)

We highlight that the collusive behavior in both stages could enhance the welfare (zones VI, VII). If we consider the social welfare equilibrium level in the Full Competition regime as the criterion value, not only the Full Collusion regime but also Semi-collusion can improve the welfare. For example, the regime $R$ is the welfare dominant regime when products are sufficiently differentiated. We find also under concavity condition, firms colluding in R\&D regardless of their production strategy always enhance more social welfare than firms colluding in output independently of R\&D strategy. Semi-collusion in Production can lead to a decrease in social welfare under convexity condition (zones I, II, III, IV). 
Although the hierarchies in terms of welfare are the same as the ones concerning consumer surplus (output) which are depicted in Sect. 3.2 (Result 2), it is clear that there are some points of dissimilarity, such as the location of the different zones and the size of zones. In virtue of this dissimilarity, the discussion on antitrust policy is unsealed. In what follows, we focus on the difference between consumer welfare standard and total welfare standard.

\subsection{Merger control: consumer welfare standard $V s$ total welfare standard}

On the basis of Result 4, we conclude that society can benefit from not only the cooperative behavior in one dimension (Semi-collusion in R\&D or in Production) but also from the horizontal merger (Full Collusion). Therefore, all regimes can yield the highest level of welfare for plausible parameter combinations.

Nowadays, most countries have laws or regulations that require competition authorities to scrutinize horizontal mergers. These authorities normally do not examine whether a particular merger is likely to affect welfare because it substantially lessens competition (USA) or significantly impedes effective competition (European Union). The US or EU applies a consumer welfare criteria to mergers. Canada, Australia and New Zealand, however, consider a merger's effects on aggregate surplus and had a very explicit aggregate surplus standard (Motta 2004).

Consequently, we make use of both total welfare standard and consumer welfare standard within our framework, to analyze the difference between two abovementioned criteria, to examine whether the merger prohibited under aggregate welfare standard can be authorized under consumer welfare standard or inversely.

From the perspective of competition policy, the regimes Full Competition and Semi-collusion in R\&D are considered as benchmarks. The competition authorities authorize the merger satisfying the following condition using total welfare standard:

$$
W^{M}>\max \left\{W^{F}, W^{R}\right\}
$$

using consumer welfare standard:

$$
\mathrm{CS}^{M}>\max \left\{\mathrm{CS}^{F}, \mathrm{CS}^{R}\right\}
$$

In Fig. 7, on the right side of curve Consumer Welfare Standard, the horizontal merger is accepted by consumer welfare standard. Total welfare standard authorizes the merger when the beach of parameter combination locates to the right of the curve named Total Welfare Standard. It is straightforward that there is the gap (dashed area) between two mentioned curves which sheds light on the looseness of the total welfare standard and the preciseness of the consumer surplus standard. Due to the prohibition by competition authorities, in the left side, the firms have to lean to the less attracting regimes which yield less profit compared to merger one. Therefore, the firms prefer the Semi-collusion in R\&D (semi-collusion ${ }^{16}$ ) in the prohibited merger zone $\left(\pi^{R}>\pi^{F}\right)$.

\footnotetext{
${ }^{16}$ Note that in reality, the Production Cartel is prohibited. Thus, we exclude it in antitrust control analysis.
} 


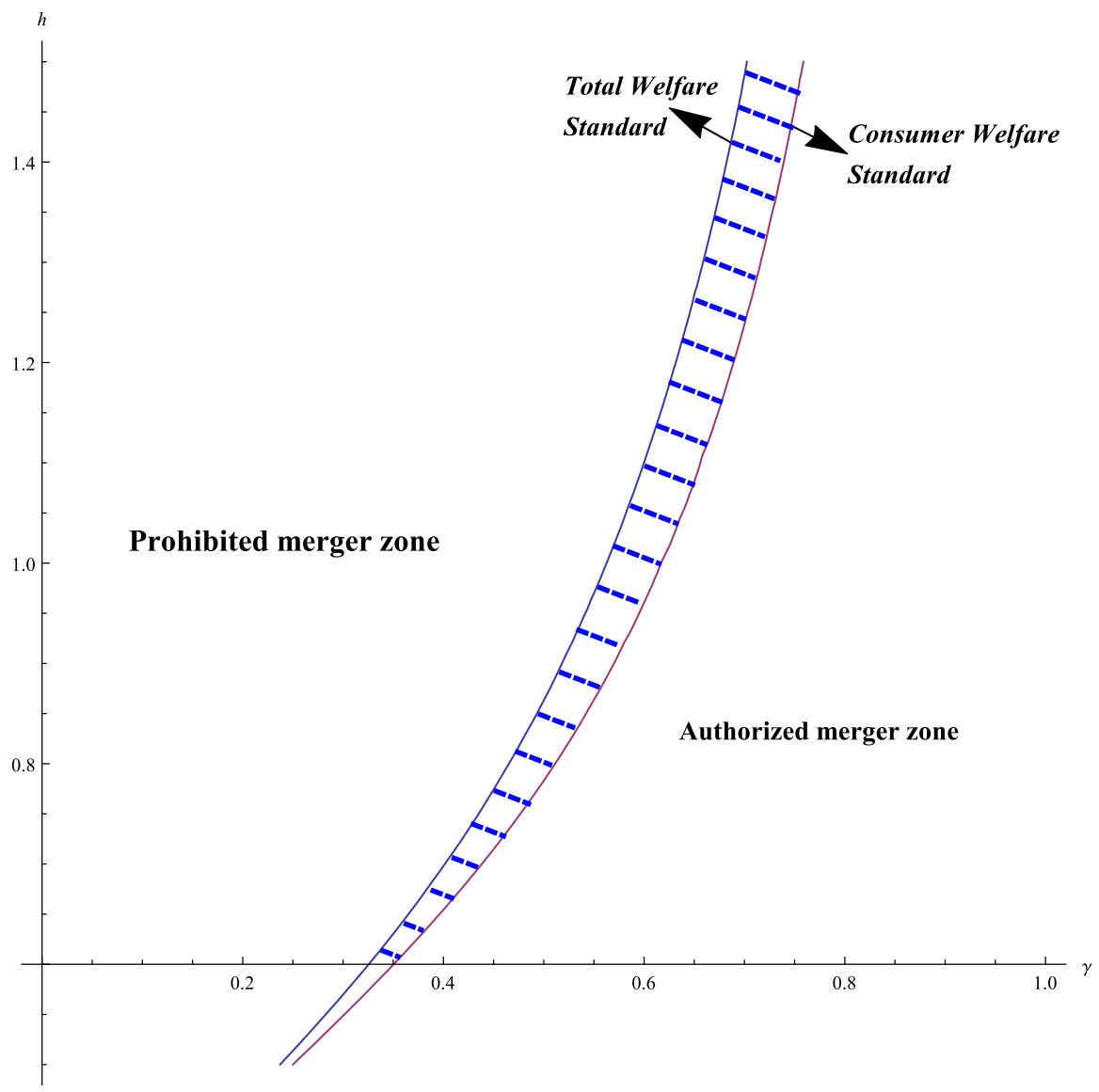

Fig. 7 Total welfare standard Vs consumer welfare standard. Source own graphic

\section{Concluding remarks}

In the traditional one-dimensional framework, collusion increases producer profits, but damages consumer welfare without ambiguity (Textbook ${ }^{17}$ view). However, this argument ignores the effects of other non-production activities, such as R\&D. Recently, as shown in Revisionist ${ }^{18}$ view, within two-dimensional game, semicollusion may be profitable and efficient (Brod and Shivakumar 1999) under some circumstances, while it can be unprofitable and inefficient. Previous works have

\footnotetext{
17 The textbook view: while the firms benefit from product market collusion, consumer welfare is higher under non-cooperation in the product market. See more in Jacquemin and Slade (1989).

18 The revisionist view: if the firms have the options for non-production activities, such as R\&D, before production, producers can be worse off and consumers can be better off. See more in Matsui (1989), Mitchell (1993) and Fershtman and Gandal (1994).
} 
shown whether producers and consumers would be better off under product market cooperation depends particularly on product differentiation and R\&D spillovers.

This paper emphasizes the "close relationship" between product differentiation and spillovers, and studies the significative relevance in the scenarios where firms can either coordinate their decisions or adopt non-cooperative strategy (Full Competition, Full Collusion and Semi-collusion regimes) at each stage. Kamien et al. (1992) claim that the investment by firms engaged in the regime $R$ is unambiguously greater than that in the regime $F$ irrespective of spillovers. We demonstrate in fact which regime generates more $R \& D$ effort in equilibrium depends upon both the degree of product differentiation and the technological distance. If we restrict our attention to the concave relationship, the ranking of R\&D efforts is unalterable and independent of the product differentiation, competitions at the upstream stage depress $R \& D$ investment. Firms colluding in $R \& D$ regardless of their production strategy always yield more profit and generate higher social welfare than firms colluding in output independently of R\&D strategy. When products are close substitutes, Full Collusion is a welfare-enhancing regime.

In addition, a discussion about antitrust policy is carried out. By focusing upon the distinctness of different antitrust criteria, this framework sheds light on the looseness of the total welfare standard and the preciseness of the consumer welfare standard. This outcome will be verified, in future work, by considering the interaction between Competition Authorities and firms, in a context of asymmetric information $^{19}$.

There are some possible extensions of this framework: first, we will check the robustness of the result obtained in this paper, when there would be more than two firms in the market; second, we will investigate whether our model can get the similar results within a dynamic ${ }^{20}$ duopoly game, by supposing the R\&D investments for cost-reducing innovation over continuous time; third, the parameter of spillover depends only on the degree of product differentiation in this model, however, the government can control the parameter of spillover using the intellectual property right policy, and it is an important extension of this model to enrich the policy implication; fourth, the degree of product differentiation is exogenously given in our model, however, firms have strategic incentives to control to maximize their profit, and it is better to consider the case that the degree of product differentiation is determined endogenously.

Acknowledgments I am grateful to Nicolas Le Pape, Thierry Penard and Bernard Franck for thoughtful comments and suggestions. I also thank Said Souam and Jean-Pascal Gayant. We have received helpful comments on earlier drafts of this article from participants at the ESEM, AFSE and seminar participants at GAINS. This work is supported by the Research Funds of Huaqiao University (HQHRZD2014-03). I am grateful for the very painstaking efforts made by the editor and the referee in providing me with very valuable suggestions and comments. All remaining errors are mine.

Conflict of interest The author declares that he has no competing interests.

\footnotetext{
19 See more in Besanko and Spulber (1989), Pénard and Souam (2002).

20 See more in Cellini and Lambertini (2009).
} 
Open Access This article is distributed under the terms of the Creative Commons Attribution 4.0 International License (http://creativecommons.org/licenses/by/4.0/), which permits unrestricted use, distribution, and reproduction in any medium, provided you give appropriate credit to the original author(s) and the source, provide a link to the Creative Commons license, and indicate if changes were made.

\section{Appendix}

\section{Appendix 1: First-best}

The social optimum R\&D effort derived from the first-best function welfare:

$$
\begin{aligned}
W\left(x_{i}, x_{j}, q_{i}, q_{j}\right)= & \sum_{i=1}^{2} \pi_{i}\left(x_{i}, x_{j}, q_{i}, q_{j}\right)+u\left(x_{i}, x_{j}, q_{i}, q_{j}\right) \\
& -\sum_{i=1}^{2} p_{i}\left(x_{i}, x_{j}, q_{i}, q_{j}\right) q_{i}\left(x_{i}, x_{j}, q_{i}, q_{j}\right)
\end{aligned}
$$

By backward induction, $q^{\mathrm{FB}}\left(x_{i}, x_{j}\right)$ is the socially First-Best output profile corresponding to $x_{i}$ and $x_{j}$. It is achieved by:

$$
q^{\mathrm{FB}}\left(x_{i}, x_{j}\right) \equiv \operatorname{argmax}_{q>0} W\left(x_{i}, x_{j}, q_{i}, q_{j}\right)
$$

Then, the first-best welfare function $W^{\mathrm{FB}}$ is defined by:

$$
W^{\mathrm{FB}}\left(x_{i}, x_{j}\right) \equiv W^{\mathrm{FB}}\left(x_{i}, x_{j}, q^{\mathrm{FB}}\left(x_{i}, x_{j}\right)\right)
$$

Finally,

$$
\begin{aligned}
x^{\mathrm{FB}} & \equiv \operatorname{argmax}_{x>0} W^{\mathrm{FB}}\left(x_{i}, x_{j}\right) \\
& =\frac{A\left(1+\gamma^{h}\right)}{(1+\gamma)-\left(1+\gamma^{h}\right)^{2}}
\end{aligned}
$$

\section{Appendix 2: Review of Brod and Shivakumar (1999)}

There are two regimes: the one is Competition where firms compete in both the R\&D and the output markets; the other one is Production Cartel where the firms compete in the R\&D market, but collude in output market. The superscript " $C$ " stands for Competition and "P" signifies Production Cartel.

The game is solved by backward induction and we characterize the equilibrium outcomes of this game.

\section{Competition}

The SPNE values of per-firm R\&D effort, output and profit are given by: 


$$
\begin{aligned}
x^{C} & =\frac{2 A}{\theta}(2-\beta \gamma) \\
q^{C} & =\frac{\delta A}{\theta}(2-\gamma)(2+\gamma) \\
\pi^{C} & =\frac{\delta A^{2} \Delta}{\theta^{2}}
\end{aligned}
$$

where $A=a-c, \quad \theta=(2-\gamma)(2+\gamma)^{2} b \delta-2(1+\beta)(2-\beta \gamma)>0$ and $\Delta=(2-$ $\gamma)^{2}(2+\gamma)^{2} b \delta-2(2-\beta \gamma)^{2}>0$.

In the paper of Brod and Shivakumar (1999), the expression of $\Delta$ displayed in page 225 is, however, $\Delta_{\mathrm{BS}}=(2-\gamma)^{2}(2+\gamma)^{2} b \delta-2(1+\beta)(2-\beta \gamma)^{2}>0$. We have $\Delta-\Delta_{\mathrm{BS}}=2 \beta(2-\beta \gamma)^{2}>0$ that generates the underestimate of the real profit.

Production cartel

The symmetric equilibrium of R\&D effort, output and profit corresponds to the following solutions:

$$
\begin{aligned}
x^{P} & =\frac{A}{\Phi}(2-(1+\beta) \gamma) \\
q^{P} & =\frac{2 \delta A}{\Phi}(1-\gamma) \\
\pi^{P} & =\frac{\delta A^{2} \Gamma}{2 \Phi^{2}}
\end{aligned}
$$

where $\Phi=\gamma+\beta^{2} \gamma+4 b \delta\left(1-\gamma^{2}\right)-2 \beta(1-\gamma)-2$ and $\Gamma=-4+8 b \delta+8 b \delta \gamma^{3}+$ $4 \gamma(1+\beta-2 b \delta)-\gamma^{2}\left(1+2 \beta+\beta^{2}+8 b \delta\right)$. As mentioned in BS, the product $b \delta$ can be expressed in the same units as output, they assume $b \delta=1$ to simplify expressions. We find whether these two expressions $(\Phi, \Gamma)$ are positive or not depends on the combination of parameters $\gamma$ and $\beta$.

Whereas, BS consider that $\Phi_{\mathrm{BS}}=4(1-\gamma)(1+\gamma)^{2} b \delta-(1+\beta)(2-(1+$ $\beta) \gamma)>0$ and $\Gamma_{\mathrm{BS}}=8(1-\gamma)^{2} b \delta-(2-(1+\beta) \gamma)>0$. Compared to our results, we have $\Phi-\Phi_{\mathrm{BS}}=-4 b \delta\left(1-\gamma^{2}\right) \gamma<0$. It is clear that there is the underestimate on $\mathrm{R} \& \mathrm{D}$ effort and output. These errors due to improper handling generate the distinctive change in the following analysis. Furthermore, BS regard mistakenly $\Phi_{\mathrm{BS}}$ and $\Gamma_{\mathrm{BS}}$ as the positive terms. Taking $\Phi_{\mathrm{BS}}$ as an example, we illustrate here $\Phi_{\mathrm{BS}}$ is negative when

- $\gamma \in(0.927441,0.927886]$ and $\beta \in\left(\tilde{\beta_{1}}, \tilde{\beta_{2}}\right)$

- $\gamma \in[0.927886,1]$ and $\beta \in\left(0, \tilde{\beta_{2}}\right)$

with $\tilde{\beta_{1}}=\frac{1-\gamma}{\gamma}-\sqrt{\frac{1-4 \gamma-4 \gamma^{2}+4 \gamma^{3}+4 \gamma^{4}}{\gamma^{2}}}$ and $\tilde{\beta_{2}}=\frac{1-\gamma}{\gamma}+\sqrt{\frac{1-4 \gamma-4 \gamma^{2}+4 \gamma^{3}+4 \gamma^{4}}{\gamma^{2}}}$.

A reappraisal of the main propositions in Brod and Shivakumar (1999).

Proposition 1 Since $\Phi_{B S}>0, B S$ claimed the $R \& D$ effort in regime Production Cartel is always significant, the firms colluding in output spared no effort to invest in $R \& D$ for $0 \leq \beta \leq 1$ and for all $0 \leq \gamma<1$. In fact, their finding is not true, the crux 


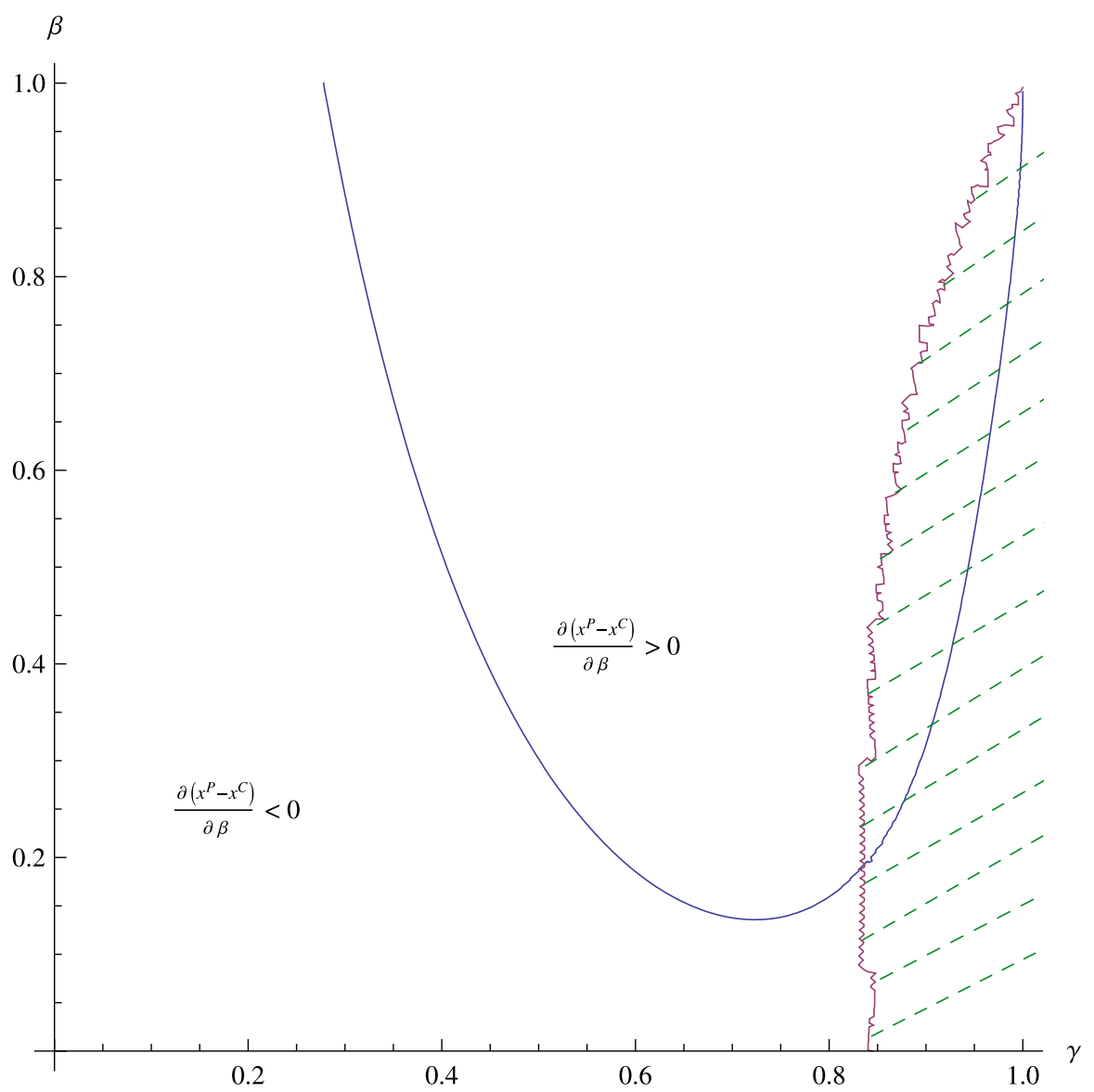

Fig. 8 The effect of $\beta$ on the difference $x^{P}-x^{C}$. Source own graphic

of the matter is that the $\Phi$ could be negative ${ }^{21}$ in certain circumscription where the optimum equilibrium $R \& D$ effort is meaningless. We find that the member firm of cartel could have no interest in $R \& D$ processes when the goods are sufficiently homogenous, precisely $\gamma \in(\hat{\gamma}, 1]$ with $\hat{\gamma}=\frac{(1+\beta)^{2}+\sqrt{33-28 \beta+6 \beta^{2}+4 \beta^{3}+\beta^{4}}}{8}$. In this instance, the $x^{P}$ will be inferior to $x^{C}$, then the proposition 1 is not always true.

In addition, Brod and Shivakumar (1999) claimed that "it is easy to show that as $\beta$ rises, the difference $x^{P}-x^{C}$ declines" in page 226 . As a matter of fact, the $\frac{\partial\left(x^{P}-x^{C}\right)}{\partial \beta}$ could be positive. Whether this gap enlarges or shrinks depends upon the combination of two parameters $\beta$ and $\gamma$. To be more legible and intuitionistic, we illustrate this outcome with the following graphic.

${ }^{21} \Phi-\Phi_{B S}=-4 b \delta\left(1-\gamma^{2}\right) \gamma<0$. 
On the basis of Fig. 8, apart from the dashed zone which represents the flaw of their proposition 1, we have not only the region, corresponding to the finding of BS, in which the relative valuation of $R \& D$ is reduced as spillovers increase, but also the region where the gap enlarges following the rise of spillovers. The primary reason of omitting this positive aspect of $\beta$ stems from the underestimate of $\mathrm{R} \& \mathrm{D}$ effort in regime $\mathrm{P}$.

Proposition 2 Brod and Shivakumar (1999) try to compare two mentioned regimes in terms of both individual and collective incentive. They consider output as an index of consumer surplus.

$$
\begin{aligned}
q^{P}-q^{C} & =\frac{2 \delta A}{\Phi}(1-\gamma)-\frac{\delta A}{\theta}(2-\gamma)(2+\gamma) \\
& =\frac{A \delta(2(1-\gamma) \theta-(2-\gamma)(2+\gamma) \Phi)}{\Phi \theta}
\end{aligned}
$$

It is straightforward, $q^{P}-q^{C}$ has the same sign as the following expression:

$$
f(\gamma, \beta)=\frac{2(1-\gamma) \theta-(2-\gamma)(2+\gamma) \Phi}{\Phi \theta}=\frac{f_{B S}(\gamma, \beta)}{\Phi \theta}
$$

Due to improper handling and error of judgement about $\Phi$, it is mistakenly deemed that the difference $q^{P}-q^{C}$ has the same sign as the expression $f_{B S}(\gamma, \beta)=$ $2(1-\gamma) \theta-(2-\gamma)(2+\gamma) \Phi=-2 \gamma^{4}+\left(\beta^{2}+2 \beta+3\right) \gamma^{3}-2 \gamma^{2}\left(2 \beta^{2}+3 \beta-3\right)-4 \gamma$ $(1-\beta)$ displayed in page 227. As the case stands, the difference $q^{P}-q^{C}$ is also influenced by the denominator $\Phi \theta$.

Concerning the difference of profit $\pi^{P}-\pi^{C}$,

$$
\begin{aligned}
\pi^{P}-\pi^{C} & =\frac{\delta A^{2} \Gamma}{2 \Phi^{2}}-\frac{\delta A^{2} \Delta}{\theta^{2}} \\
& =\frac{A^{2} \delta\left(\Gamma \theta^{2}-2 \Delta \Phi^{2}\right)}{2 \Phi^{2} \theta^{2}} \\
& \neq \frac{A^{2} \delta\left(\Gamma_{B S} \theta^{2}-2 \Delta_{B S} \Phi_{B S}^{2}\right)}{2 \Phi_{B S}^{2} \theta^{2}}
\end{aligned}
$$

it is straightforward that $\pi^{P}-\pi^{C}$ has the same sign as

$$
g(\gamma, \beta)=\Gamma \theta^{2}-2 \Delta \Phi^{2} \neq \Gamma_{B S} \theta^{2}-2 \Delta_{B S} \Phi_{B S}^{2}
$$

According to Fig. 2 in Brod and Shivakumar (1999) page 228, there are always $q_{\mathrm{BS}}^{P}>q_{\mathrm{BS}}^{C}$ and $\pi_{\mathrm{BS}}^{P}<\pi_{\mathrm{BS}}^{C}$ in region $\mathrm{D}$. Practically, we can find the inverse outcome $q^{P}<q^{C}$ even $\pi^{P}>\pi^{C}$ in this region. 


\section{References}

Amir R (2000) Modelling imperfectly appropriable R\&D via spillover. Int J Ind Organ 18(7):1013-1032 Audretsch D, Feldman M (1996) Knowledge spillovers and the geography of innovation and production. Am Econ Rev 86(3):630-640

Baptista R, Swann P (1998) Do firms in clusters innovate more? Res Policy 27:525-540

Besanko D, Spulber DF (1989) Antitrust enforcement under asymmetric information. Econ J 99:408-425

Brod A, Shivakumar R (1999) Advantageous semi-collusion. J Ind Econ 47(2):221-230

Cellini R, Lambertini L (2009) Dynamic R\&D with spillovers: competition vs cooperation. J Econ Dyn Control 33(3):568-582

D'Aspremont C, Jacquemin A (1988) Cooperative and noncooperative R\&D in duopoly with spillovers. Am Econ Rev 78:1133-1137

Fershtman C, Gandal N (1994) Disadvantageous semicollusion. Int J Ind Organ 12:141-154

Henriques I (1990) Cooperative and noncooperative R\&D in duopoly with spillovers: comment. Am Econ Rev 80:638-640

Jacquemin A, Slade M (1989) Cartels collusion and horizontal merger. Handbook of industrial organization (New York, North-Holland)

Kamien M, Muller E, Zang I (1992) Research joint ventures and R\&D cartels. Am Econ Rev $82: 1293-1306$

Matsui A (1989) Consumer-benefited cartels under strategic capacity investment competition. Int J Ind Organ 7:451-470

Mitchell S (1993) The welfare effects of rent-saving and rent-seeking. Canad J Econ 26:660-669

Motta M (2004) Competition policy: theory and practice. Cambrige University Press, pp 579

Pénard T, Souam S (2002) Collusion et politique de la concurrence en information asymétrique. Ann d'éonomie et de Stat 66:209-233

Piga C, Poyago-Theotoky J (2005) Endogenous R\&D spillovers and locational choice. Regional Sci Urban Econ 35:127-139

Severinov S (2001) On information sharing and incentives in R\&D. RAND J Econ 32:542-564

Suzumura K (1992) Cooperative and noncooperative R\&D in an oligopoly with spillovers. Am Econ Rev 82:1307-1320

Suzumura K, Yanagawa N (1993) Cooperative and noncooperative R\&D in an oligopoly with spillovers: strategic substites vesrsus strategic complements. Hitotsubashi J Econ 34:1-11 